\title{
Exploring Fundamental Causes of Safety Challenges Faced by Hispanic Construction Workers in the US using Photovoice
}

\section{INTRODUCTION}

Construction is one of the largest and most dangerous industries in the United States. In 2010 the industry contributed to $3.5 \%$ of the total gross domestic product and, in the same year, employed 7\% of the U.S. workforce (Center for Construction Research and Training 2013). According to the U.S. Bureau of Labor Statistics (2012), the construction industry accounted for a total of 802 fatalities in the most recent census. This is the lowest annual count ever recorded; however, construction still resulted in more fatalities than any other industry. In terms of non-fatal injuries resulting in days away from work, the construction industry ranked third among all major industries with a rate of 149.6 recordable injuries per every 10,000 full-time equivalent workers (Center for Construction Research and Training 2013). Moreover, construction workers generally take longer to recover from injuries than workers in other industries. Specifically, the 2010 rate of cases requiring a full month or more away from work was 50 per 10,000 full-time employee whereas the rate was only 30 per 10,000 full-time employees for the all-industry average.

Unlike other industries where processes are streamlined and outcomes are relatively stable, the construction industry has a project-based, dynamic, and transient nature. Work conditions are never the same between projects, the final product is always different, the type of work required is varied, the labor force is very diverse, and there is a high degree of turn-over (Fang et al. 2006). This mixture of characteristics contributes to the disproportionate injury rate in construction.

Within this high risk industry, data reported by the Center for Construction Research and Training (2013) shows that the fatality rate for Hispanic construction workers was, on average, $48 \%$ higher than for non-Hispanic workers. This disproportionate injury rate is compounded by the fact that the proportion of Hispanic construction workers has been increasing in the last two decades. Recent census data show that the number of Hispanic construction workers has tripled between 1990 and 2010, rising from 705,000 to 2.2 million workers (Bureau of Labor Statistics 2012). This increase has resulted in a situation where Hispanic workers are majorities in the construction industry in states such as New Mexico (representing 57\% of the workforce), Texas (55\%), and Colorado (48\%). In addition, the Hispanic population in the US is expected to double from 53.3 million in 2012 to 128.8 million in 2060 while the non-Hispanic white population is expected to peak by 2024 at 199.6 million. The disproportionately high injury rate for Hispanic workers, compounded with the expected increases in the proportion of Hispanic workers, is a critical concern for construction safety management. Thus, research is needed to identify factors that may contribute to disproportionate injury rates for this demographic.

The objective of this research is to capture the behaviors, interpersonal relationships, biases, perceptions of authority, emotional reactions to safety situations, and other factors that relate to the cultural distance between Hispanic and non-Hispanic workers. We aim to address the disparity in injury rates by better understating the specific safety implications of cultural differences on construction sites. For the first time, we derive knowledge from the Hispanic 
population directly without using preconceived notions. New safety interventions specific to the Hispanic population may be created with this increased knowledge.

\section{LITERATURE REVIEW}

Studying the factors that influence the safety of Hispanic construction workers requires a thorough review of prior research. Additionally, research on the effects of varied national cultures helps to identify probable cultural differences between the Hispanic and the nonHispanic cultures. For consistency it is important to define the demographic populations of interest. Here, Hispanic workers are broadly defined as those workers whose ethnicity can be directly traced to Spanish or Spanish-speaking countries of origin. In the US construction industry, these workers are primarily Mexican. Alternatively, we classified non-Hispanic US workers as defined predominantly as White workers who are descendants of European countries. Although this is not the predominant definition of 'non-Hispanic,' we avoided the use of the term White because there are many workers discussed as non-Hispanic who are European, African American, and Asian. Thus, the term non-Hispanic here refers to the Hispanic workers' coworkers who were not of Hispanic descent.

The following sections describe the literature related to cultural differences between Hispanic and non-Hispanic workers and factors that drive Hispanic safety issues such as culturallyinfluenced behaviors, work assignments, language and communication, and other factors. This literature is then used to frame the intellectual and practical contributions of the present research across multiple knowledge domains.

\subsection{Cultural Differences - Hispanic vs. non-Hispanic workers}

The concept of multi-national culture, defined as the group programming of the mind that is acquired by long-term childhood exposure to a particular country, has been widely studied and several theories and frameworks have been developed (Hofstede 1980; 2001; 2005; Lenartowicz and Roth 1999; Soares et al. 2007). Among these frameworks, Hofstede's (1980; 2001) crosscultural analysis has been widely validated and is the most generalizable. Initially, Hofstde (1980) included four dimensions and in subsequent revisions (e.g., Hofstede 2001; 2005) included new dimensions because culture is dynamic. Most recently, he has used 116,000 surveys from over 60,000 respondents in 70 countries and revised the model to define countryspecific indexes for the following six cultural dimensions: power distance, uncertainty avoidance, individualism, masculinity, pragmatism, and indulgence. It should be noted that Hofstede's index is not an objective metric or indicator as an index is traditionally defined. Rather, it is an indicator of the extremity of the qualitative cultural differences. Also, since the scale is subjective and qualitative in nature, the actual metrics on the Hofstede scale are not objectively meaningful. It should also be noted that the descriptions in Table 1 of the various cultural dimensions should be reviewed with caution because culture is dynamic.

The index does allow for cross-country cultural comparisons and the estimation of cultural distance. Table 1 provides a definition of each relevant cultural dimension, a description of the predominant characteristics of Mexican culture and US culture for each dimension, and Hofstede's subjective index score. Although all Latin American countries are represented in the US construction workforce and are represented in Hofstede's model, Mexico was selected to illustrate cultural distance for brevity and because it is the country of origin for the vast majority 
of Hispanic workers in the US. Also, Mexico is representative of Latin American countries in all salient cultural dimensions.

Despite the geographical proximity of the US and Mexico, there are vast differences in cultural norms. For example, when compared to the US, Mexicans: (1) have a much higher power distance index than the U.S., which in organizational settings reflects a strong discomfort with challenging perceived authority; (2) are more collectivist, which reflects the importance of the direct family and the extended family; and (3) are less accepting of uncertainties than the U.S. and, as result, are more likely to have trouble accepting new ideas. Such differences suggest that there is a mismatch between Hispanic and non-Hispanic workers' cultures that could translate into construction safety challenges.

There has been some criticism of the use of Hofstede's cultural dimensions indexes for numerical and statistical comparisons between countries (Canales et al. 2009). Critics argue that culture cannot be summarized into these five categories because culture is such a broad concept that has multiple definitions, some of which go beyond what these five represent. However, Hofstede's theory still represents a well-cited framework that can be used as a starting point to develop research questions and a point of departure. In this study, we attempt to collect data independent of these dimensions but make comparisons to Hofstede's dimensions in the interpretation of results and formation of conclusions.

\subsection{Hispanic Construction Worker Safety}

In addition to understanding cultural distance between Hispanic and non-Hispanic workers, researchers have explored the consequences of cultural distance on behavior, communication, work assignments, and other factors that impact construction safety.

\subsubsection{Culturally-Influenced Behaviors}

Many authors suggest that the high fatality and injury rates among Hispanic construction workers are influenced by behavioral differences between Hispanic workers and their White counterparts (Brunette 2004; Farooqui et al. 2007; Lavy et al. 2010; Menzel and Gutierrez 2010). Farooqui et al. (2007) conducted root cause analyses of workplace injuries among Hispanic construction workers and found that many Hispanic construction workers are fearful of authority. An example implication of this phenomenon is the observed trend of Hispanic workers not requesting adequate personal protection equipment (PPE) when needed for fear of retaliation from their employers (Farooqui et al. 2007). Menzel et al. (2010) surveyed 30 union and nonunion Hispanic workers and found corroborating evidence. Their findings also suggest Hispanic 
Table 1 - Cultural comparison between Mexico and the United States

\begin{tabular}{|c|c|c|c|c|c|}
\hline Dimension & Definition & Mexico & Index & United States (US) & Index \\
\hline $\begin{array}{l}\text { Power } \\
\text { Distance }\end{array}$ & $\begin{array}{l}\text { The extent to which a } \\
\text { national culture accepts } \\
\text { and reinforces that } \\
\text { power in institutions } \\
\text { and organizations is } \\
\text { distributed unequally }\end{array}$ & $\begin{array}{l}\text { Hierarchical society. People accept a } \\
\text { hierarchical order in which everybody has a } \\
\text { place. Hierarchy in an organization is seen as } \\
\text { reflecting inherent inequalities, centralization } \\
\text { is popular, subordinates expect to be told what } \\
\text { to do and the ideal boss is a benevolent } \\
\text { autocrat. }\end{array}$ & 81 & $\begin{array}{l}\text { Within American organizations, hierarchy is } \\
\text { established for convenience, superiors are always } \\
\text { accessible and managers rely on individual employees } \\
\text { and teams for their expertise. Both managers and } \\
\text { employees expect to be consulted and information is } \\
\text { shared frequently. Communication is informal, direct, } \\
\text { and participative }\end{array}$ & 40 \\
\hline $\begin{array}{l}\text { Uncertainty } \\
\text { Avoidance }\end{array}$ & $\begin{array}{l}\text { The degree to which a } \\
\text { national culture values } \\
\text { the reduction of } \\
\text { uncertainty and } \\
\text { ambiguity }\end{array}$ & $\begin{array}{l}\text { High preference for avoiding uncertainty. } \\
\text { Mexican culture has rigid codes of belief and } \\
\text { behavior, and people are intolerant of } \\
\text { unorthodox behavior and ideas. There is an } \\
\text { emotional need for rules and people have an } \\
\text { internal need to be busy. }\end{array}$ & 82 & $\begin{array}{l}\text { American society could be described as uncertainty } \\
\text { accepting. There is acceptance of innovative ideas, and } \\
\text { willingness to try something new or different }\end{array}$ & 46 \\
\hline $\begin{array}{l}\text { Individualism } \\
\text { - Collectivism }\end{array}$ & $\begin{array}{l}\text { The degree of } \\
\text { interdependence a } \\
\text { society maintains } \\
\text { among its members }\end{array}$ & $\begin{array}{l}\text { Mexicans have long-term commitment and } \\
\text { greater importance of the group which can be } \\
\text { family, extended family, or extended } \\
\text { relationships. There is also strong collective } \\
\text { responsibility }\end{array}$ & 30 & $\begin{array}{l}\text { American society is highly individualistic. There is a } \\
\text { loosely-knit society where the expectation is that } \\
\text { people look after themselves and their immediate } \\
\text { family. In organizational terms, employees are expected } \\
\text { to be self-reliant and display initiative }\end{array}$ & 91 \\
\hline $\begin{array}{l}\text { Masculinity - } \\
\text { Femininity }\end{array}$ & $\begin{array}{l}\text { Masculinity refers to a } \\
\text { desire to be the best } \\
\text { while femininity points } \\
\text { to enjoyment of life }\end{array}$ & $\begin{array}{l}\text { Mexico is a masculine society where people } \\
\text { "live in order to work". Here, managers are } \\
\text { expected to be decisive and assertive. }\end{array}$ & 69 & $\begin{array}{l}\text { American society is a masculine society. Similarly, to } \\
\text { Mexico, Americans live to work as the society } \\
\text { recognizes that people should strive to be the best they } \\
\text { can be and that the goal is to win }\end{array}$ & 62 \\
\hline $\begin{array}{l}\text { Pragmatic - } \\
\text { Normative }\end{array}$ & $\begin{array}{l}\text { Describes how people, } \\
\text { relate to the fact that so } \\
\text { much of what happens } \\
\text { around us cannot be } \\
\text { explained }\end{array}$ & $\begin{array}{l}\text { The Mexican society can be characterized as } \\
\text { normative. This means that people have a } \\
\text { strong concern with establishing the absolute } \\
\text { truth, and show a great respect for traditions, } \\
\text { and focus on quick results. }\end{array}$ & 24 & $\begin{array}{l}\text { American culture is normative. Americans are prone to } \\
\text { verification of new information. American businesses } \\
\text { measure their performance on a short-term basis, with } \\
\text { profit and loss statements issued on a quarterly basis. }\end{array}$ & 97 \\
\hline $\begin{array}{l}\text { Indulgence - } \\
\text { Restraint }\end{array}$ & $\begin{array}{l}\text { Refers to the extent to } \\
\text { which people try to } \\
\text { control their desires and } \\
\text { impulses based on the } \\
\text { way they were raised. }\end{array}$ & $\begin{array}{l}\text { Mexico is a very indulgent country. People } \\
\text { look to realize their impulses and desires with } \\
\text { regard to enjoying life and having fun. There is } \\
\text { a high degree of importance on leisure time. }\end{array}$ & 97 & $\begin{array}{l}\text { Although the U.S. ranks lower than Mexico on this } \\
\text { Dimension, the American culture can be characterized } \\
\text { as indulgent. Some examples of this attitude are: The } \\
\text { work hard play hard idea; Although there is a strong } \\
\text { war against drugs, drug addiction in the U.S. is higher } \\
\text { than in many other wealthy countries }\end{array}$ & 68 \\
\hline
\end{tabular}


workers underreport injuries. Finally, Smith et al. (2006) observed familismo, which is related to the strong family ties displayed by many Latin American cultures. An example of the effect of familismo can be found when Hispanic workers consider their crew members to be a part of their extended family, which can result in cliques and small functional groups on large sites.

\subsubsection{Work Assignments}

Goodrum and Dai (2005) and Menzel and Gutierrez (2010) suggest that there is a correlation between the type of work assigned to Hispanic workers and their high injury and fatality rates. Using Bureau of Labor Statistics data, the Center for Construction Research and Training (2013) found that, between 2008 and 2010, the Laborer and Carpenter trades were the two most common for Hispanic construction workers. The same study revealed that Laborer and Carpenter accounted for the most fatalities and non-fatal injuries resulting in days away from work. Additionally, based on the risk perceptions of Hispanic workers in Southern Nevada, Menzel and Guttierrez (2010) revealed that those workers with low skill level positions (e.g., painters and laborers) perceived more risk than those performing higher skill work (sheet metal workers). Laborers and painters noted that they are more willing to perform high risk work because they are afraid of being fired if they complained in part due to their immigration status.

\subsubsection{Language and Communication}

A component of culture, language has proven to be a significant barrier for Hispanic workers. According to the Center for Construction Research and Training (2013) about $45 \%$ of Hispanic immigrant workers cannot speak English fluently and over 25\% cannot speak English at all. This issue affects their understanding of training materials and safety signals provided by the employer. More importantly, however, the lack of English proficiency directly affects safety communication among workers and between workers and management on a construction site. Alsamadani et al. (2013) used social network analysis to study this issue with small construction work crews. They found that, in the case where the members of a crew speak only one language, the crews have an average injury rate that is $51 \%$ lower than crews whose members prefer to speak more than one language. Jaselskis et al. (2008) conducted a needs assessment among construction companies and found that $75 \%$ of American construction supervisors have a translator who helps them communicate with Spanish-speaking workers. The need for translators illustrates the inability of American supervisors to directly communicate with all crew members, which ultimately reduces the effectiveness of their communication.

\subsubsection{Other Factors}

In addition to culture and communication issues, literature shows that there are other factors that contribute to higher injury and fatality rates for Hispanic workers. Roelofs et al. (2011) surveyed two groups of Hispanic construction workers and found that they feel more pressure to work faster than their non-Hispanic counterparts. In addition, non-Hispanic workers have more knowledge of their rights as employees and therefore know when to report injuries or raise concern when treated unfairly. Finally, most Hispanic workers have a fear of losing their job if they raise safety concerns, which translates to a higher risk tolerance than non-Hispanic workers. 


\subsection{Limitations of past research}

As discussed, many researchers have studied the causes of the disproportionate injury rate for Hispanic construction workers (Canales et al. 2009; Goodrum and Dai 2005; Menzel and Gutierrez 2010; Roelofs et al. 2011). However, there are two main limitations of this past research that will be addressed in the present research.

First, previous investigators have generally used presupposed ideas to develop research frameworks and tools to gather data from workers and managers. These preconceptions typically take the form of survey and interview questions that severely limit the validity of the associated results. A common consequence is spurious, partial, or fragmented discussion of the topic. Conversely, this study explores the perceived cultural and personal challenges that impact the safety of Hispanic construction workers using Photovoice, a systematic method that allows each participant to be the generator of their own data without input or bias from the researchers. To our knowledge, Photovoice has never been used to study worker safety issues, despite the fact that it has roots in research on vulnerable populations (Hergerather et al. 2009). Additionally, Photovoice has not seen widespread use in the construction engineering and management domain either. Presumably, photovoice has not seen a great deal of use because it is far more resource and time intensive when compared with traditional interviews, focus groups, and surveys, which can be conducted more flexibly.

Second, given that a majority of Hispanic construction workers were born outside of the US and the evidence provided by previous research that language (Alsamadani et al. 2013) and personal values play a role in Hispanic worker safety (Menzel and Gutierrez 2010; Roelofs et al. 2011), the difference between the national cultures may be a potential explanation for the disproportionate injury rates (Hofstede 1980). This study focuses on the interplay among the many dimensions of culture using experiential data solicited directly from the workforce without presupposition.

\section{RESEARCH METHODS}

The research protocol was divided into two parts: an exploratory focus group phase and the Photovoice phase. The purpose of the focus group was three-fold: (1) to gather preliminary data from the participants in an informal setting; (2) build rapport with the participants and to introduce the Photovoice process; and (3) develop Photovoice themes from the data to be used in the second phase. Photovoice was the primary data collection method employed and resulted in rich, novel findings. The various steps involved in the two phases are shown in Figure 1 and are described in detail.

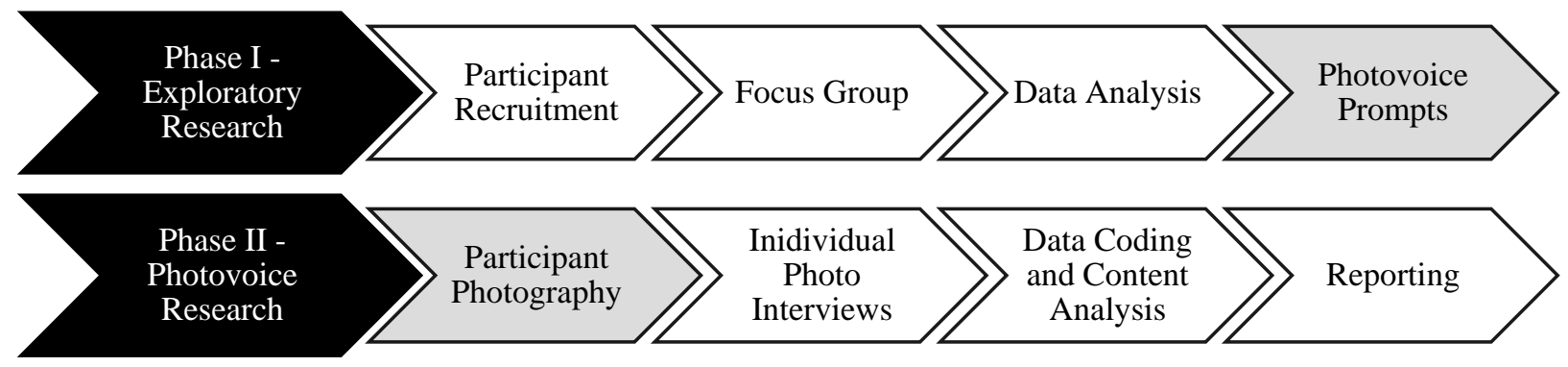

Figure 1 -Primary longitudinal research steps 


\subsection{Participant recruitment}

Our objective was to include the same subjects in the exploratory interviews and the Photovoice portions of the study to ensure that the experience of the subject group were integral to the entire process. The requirements of the Photovoice phase dictated the sample size needs for the entire study. Past Photovoice studies have a broad range in the number of participants. In a review of 31 Photovoice studies, Hergerather et al. (2009) found that the number of participants ranged from 4 to 122, and that the average participant number was 20.9. Hergerather et al. (2009) also noted that saturation and replication were observed most commonly after the $14^{\text {th }}$ Photovoice interview. Thus, our team decided to recruit between 15 and 20 participants for the entire twophase study.

In order to recruit participants, several project leaders at different construction sites in Colorado were contacted. Five contractors agreed to participate in the study and the research team approached the workforce soliciting voluntary participation. Workers in the laborer and carpenter trades were the initial focus of the recruitment because, as stated before, most Hispanic workers are employed in these trades and they are the most dangerous trades in the industry. However, workers from other trades (iron workers and pipefitters) were included to reach our target population size and to enhance generalizability. In total, 17 workers completed the entire Photovoice study.

\subsection{Focus groups}

The focus group method were chosen to collect initial exploratory data because it allows the research team to gather large amounts of information in relatively short periods of time, permits the generation of insights into topics that were not previously well understood, and allows the investigator to explore unanticipated topics without the need of complex sampling techniques (Berg 2009). Focus groups have been widely used in studies with similar objectives such as obtaining general background information about a topic of interest, gathering research hypothesis that can be used for further research, and learning how respondents talk about a qualitative phenomenon of interest that can be explored more quantitatively with other methods.

Before conducting the focus group meetings, the research protocol and the benefits were discussed with the participants. Additionally, informed consent was obtained in accordance with the Internal Review Board (IRB) protocol. During the interviews the workers were told that there were no right or wrong answers. Given that this stage was only exploratory and one of its objectives was to build rapport with participants, interviews were conducted in an informal setting. Refreshments were provided as some researchers have found that eating promotes conversation (Krueger and Casey 2000). For the first phase, the interviews were not audio taped in order to the make the participants feel more comfortable with the investigation, although the research team captured copious notes.

Open-ended questions were preferred over close-ended questions as they allow participants to answer the questions in their own words rather than obligating them to select their answers from a predetermined set of responses (Foddy 1993). Also, the questions, shown in Table 2, were crafted and ordered to prevent the introduction of researcher biases as suggested by Halcomb et al. (2007). The first three questions allowed participants to get familiar with the research objective and stimulated participation. The next two were the key research questions, which are 
designed to generate discussion about the unique safety challenges faced by Hispanic workers and explore the role of culture. The final question aimed to codify the results and solicit final comment. Collectively, the responses to these research questions were used to compare with existing literature and to collect participant-generated Photovoice prompts.

The focus group discussions were facilitated by a Hispanic research assistant who is fluent in both English and Spanish. Umaña-Taylor and Bámaca (2004) suggest, from their experience on focus group research in Latino populations, a facilitator who is from the same origin than the participants as this disinhibits the participants and enriches discussion. Therefore, the authors feel that the demographic of the research team was a strong asset that enhanced the validity and reliability of the final results. Given that the researcher was embedded in the group for a period of time, identifies as the same national culture as the group under investigation, held interviews with the workers in the workplace and in informal settings (e.g., lunch), we consider this research to be a social constructivist approach. As we present findings, our goal is to explain the perceptions that we heard in context. As such, we were not merely observers and the data presented here are not purely objective.

\section{Table 2: Photovoice steps}

\begin{tabular}{|c|c|c|c|}
\hline No & Step & Goal & Specific activities \\
\hline 1 & $\begin{array}{l}\text { Connect with } \\
\text { the community }\end{array}$ & $\begin{array}{l}\text { Identify, connect, and build trust } \\
\text { with a target community in order to } \\
\text { identify a challenge or issue. Also, } \\
\text { obtain IRB approval, meeting } \\
\text { locations, and other approvals. }\end{array}$ & $\begin{array}{l}\text { IRB approval was obtained through the } \\
\text { University of Colorado prior to contacting } \\
\text { participants. A literature review was also } \\
\text { conducted to identify knowledge gaps and study } \\
\text { objectives. A Hispanic researcher with } \\
\text { construction experience was selected to lead the } \\
\text { effort to better connect with the community. }\end{array}$ \\
\hline 2 & $\begin{array}{l}\text { Recruit } \\
\text { participants }\end{array}$ & $\begin{array}{l}\text { Identify and assemble participants } \\
\text { who will complete the Photovoice } \\
\text { process. }\end{array}$ & $\begin{array}{l}\text { Workers were recruited through their employers } \\
\text { and with announcements at the construction site. } \\
\text { All participation was voluntary, anonymous, and } \\
\text { uncompensated per our IRB approval. }\end{array}$ \\
\hline 3 & $\begin{array}{l}\text { Introductory } \\
\text { group meeting }\end{array}$ & $\begin{array}{l}\text { Conduct a group meeting to share } \\
\text { the study goals obtain informed } \\
\text { consent. Teach participants how to } \\
\text { use the cameras, develop } \\
\text { photography themes, and provide } \\
\text { recommendation for protecting } \\
\text { human subjects. }\end{array}$ & $\begin{array}{l}\text { The initial group meeting was held in the form } \\
\text { of the focus group previously described. In this } \\
\text { meeting the goals of the study, timeline, and } \\
\text { other logistics were introduced. Informed } \\
\text { consent was obtained and all directions for the } \\
\text { study were provided. }\end{array}$ \\
\hline 4 & $\begin{array}{l}\text { Individual data } \\
\text { collection }\end{array}$ & $\begin{array}{l}\text { Participants capture the photographs } \\
\text { in order to tell their story. }\end{array}$ & $\begin{array}{l}\text { Workers captured photographs of safety issues } \\
\text { that they face that relate directly to their culture } \\
\text { and identity. Photos were taken over the course } \\
\text { of two weeks using disposable cameras provided } \\
\text { by the research team. }\end{array}$ \\
\hline 5 & $\begin{array}{l}\text { Individual } \\
\text { interviews with } \\
\text { subjects }\end{array}$ & $\begin{array}{l}\text { Participants share their photos with } \\
\text { the research team and describes the } \\
\text { phenomena contained therein. }\end{array}$ & $\begin{array}{l}\text { The workers chose their best pictures and } \\
\text { discussed their stories individually. These } \\
\text { interviews were audio recorded and transcripts } \\
\text { were produced. }\end{array}$ \\
\hline 6 & $\begin{array}{l}\text { Data analysis } \\
\text { and reporting }\end{array}$ & $\begin{array}{l}\text { The themes in the Photovoice } \\
\text { interviews are identified and } \\
\text { described. }\end{array}$ & $\begin{array}{l}\text { A combination of manual and automated content } \\
\text { analysis of interview transcripts was used to } \\
\text { objectively identify trends in the interviews. }\end{array}$ \\
\hline
\end{tabular}




\subsection{Photovoice protocol}

The results of the focus group discussions were used as initial prompts for Photovoice where the unit of analysis shifted from groups to individual workers. As previously discussed, the unique contribution of this study was the solicitation of rich experiential data directly from the population of interest without presupposition. Photovoice is a new method to the safety research domain, which allows the research community to engage with research subjects in a way that allows for very rich data collection that is participant centered and controlled.

\subsubsection{Background}

Photovoice is a qualitative research technique that involves the use of photographs in an interview. The term Photovoice was introduced by Collier (1957) who used photographs on an investigation of mental health in changing communities in the maritime provinces of Canada. They expressed that the pictures elicited longer and more comprehensive interviews while at the same time "helped subjects overcome the fatigue and repetition of conventional interviews" (Collier 1957 p. 857). This effect can be explained by the fact that the parts of the human brain that processes visual information is evolutionarily older than the parts that process verbal information; thus, images evoke to deeper elements of human consciousness than do words (Harper 2002). Other advantages of using pictures in interviews are that photographs can promote rapport between the researchers and the participants and reduce awkwardness between the researchers and the participants (Samuels 2004).

Photovoice can be viewed as a method to empower vulnerable populations, acknowledging that the participants have the best knowledge about their own situation. One main advantage of the method is that it is flexible and can be adapted to various participatory research goals and any group or community. It does not require participants to be able to read or write, speak the research's dominant language, or be fully literate in any language. Examples of Photovoice application are the research on social health issues of women in rural communities of China (Wang 1996), research on indigenous populations in Canada (Castleden et al. 2008), effects of immigration in the lives of Latino adolescents (Streng et al. 2004), or investigation on improving family planning services for immigrant Hispanics (Schwartz et al. 2007).

Photovoice is based firmly on established theories of participant-based research. Specifically, it is grounded in the following two theories:

1. Theory of critical consciousness (Freire 1970), which seeks the engagement of individuals in the questioning of their historical and social situation using visual images that enable people to think critically about their community (Wang and Burris 1997).

2. Theory of documentary photography (Castleden et al. 2008), which shows that providing a camera to people who might not normally have access to one will empower them to record and instigate change in their communities.

Palibroda et al. (2009) describe six steps required to conduct a rigorous Photovoice study. These steps are concisely described in Table 3 . Although these steps were designed for research on the field of women's health, other researchers studying community improvement, quality of life improvement, and living with disabilities have also followed a similar procedures (Hergenrather et al. 2009). Steps 3, 5, and 6 are described in greater detail because the specific research activities affect the validity and reliability of the final results. 
Table 3 - Focus group questions

\begin{tabular}{|l|l|}
\hline $\begin{array}{l}\text { Introductory } \\
\text { Question }\end{array}$ & $\begin{array}{l}\text { Please tell us your first name and the first thing that comes to your mind when talk about safety } \\
\text { and Hispanic workers. }\end{array}$ \\
\hline $\begin{array}{l}\text { Transition } \\
\text { Question }\end{array}$ & $\begin{array}{l}\text { What challenges do you face as a construction worker that you think negatively impact your } \\
\text { safety? }\end{array}$ \\
\hline $\begin{array}{l}\text { Transition } \\
\text { Question }\end{array}$ & Explain any safety differences between Hispanic and non-Hispanic construction workers? \\
\hline Key Question & $\begin{array}{l}\text { Recent statistics show that Hispanic workers suffer more fatal accidents than non-Hispanic } \\
\text { workers in the construction industry. What do you think explains this issue? }\end{array}$ \\
\hline Key Question & $\begin{array}{l}\text { People that were raised entirely or in part with some influence from a foreign country usually } \\
\text { have their own ways doing things that are very specific to where they are from (culture). In } \\
\text { what way does your cultural experience play a role in construction safety? }\end{array}$ \\
\hline Key Question & $\begin{array}{l}\text { Please discuss how interacting with people whose culture is different from your own affects } \\
\text { your safety experiences? }\end{array}$ \\
\hline $\begin{array}{l}\text { Closing } \\
\text { question }\end{array}$ & $\begin{array}{l}\text { As you know, the purpose of this focus group is to identify the themes that we will use on the } \\
\text { next phase to capture pictures at the site. What topics do you think are appropriate that will } \\
\text { help us understand how culture affects safety? }\end{array}$ \\
\hline
\end{tabular}

\subsubsection{Introductory Meeting}

The participants were recalled to an introductory meeting a week after completion of their focus group. This meeting had two main purposes. First, the participants were instructed on the use of the disposable cameras. The workers not only received instruction on the mechanical aspects of the camera but they were also given some basic photography tips such as keeping their fingers out of the camera lenses, placing the sun at their back as often as possible, and trying to show not only the object of interest but also some background. The researchers tried to keep the technical advice to a minimum in order to minimize the effects on their creativity as suggested by Wang (1996). Second, the participants received their Photovoice assignment that was drawn from the results obtained from the focus group discussions (explained in the results section). The participants were asked to capture any object, individual, condition, object, etc. that related to the prompts. They were asked to capture things that they felt were different for them as Hispanic workers than for their non-Hispanics colleagues, as well as things that they felt were exclusive to them as Hispanic workers. The participants were given approximately two weeks to complete the assignment.

\subsubsection{Individual Photovoice interviews}

Upon completion of the Photovoice assignment the cameras were collected and the photographs were processed. All the cameras were marked with identifiers related to each participant. One week after completion of the photo assignments the author proceeded to interview the participants to discuss their photographs. Wang and Burris (1997) and Palibroda et al. (2009) suggest the use of group discussions to collect the reflections of the participants on their photographs. However, Hallowell and Gambatese (2010) elucidated a variety of issues that can cause biases in the collection of data in group settings not considered by Wang and Burris (1997) and Palibroda et al (2009). One of these biases is the issue of dominance, which happens when one group member, usually very vocal and intimidating, dominates the discussion and opinions 
of others (Hallowell and Gambatese 2010), especially those with a quiet personality who prefer to remain silent even though they have their own opinions. Furthermore, another issue that can come from a group setting is the "bandwagon effect," which describes how individuals unconsciously feel pressure to conform to the common or standard beliefs within a group (Hallowell and Gambatese 2010). Since the first phase involved focus groups and in order to avoid these cognitive biases, the team chose to conduct individual interviews with the participants. This method also promoted a larger database and more individual participation as each worker was requested to discuss several photographs.

\subsubsection{Content analysis of interview transcripts}

The research team first transcribed the interviews verbatim in Spanish. Then, in order to reduce bias in the interpretation of the information, two researchers who speak both Spanish and English fluently analyzed each transcription separately. The transcriptions were then compared and any discrepancies were rectified. To safeguard the privacy of the participants and their employers the team replaced all personal identifiers and company names in the transcriptions. The materials were analyzed using QSR NVIVO, a code and retrieval software system for content analysis of qualitative data.

Content analysis is a method of detecting, recording, and analyzing the presence of words, phrases, and other written form of communication within a larger volume of text (Walter 2010). Here, the goal was to use content analysis to systematically decompose and organize the relevant content of Photovoice transcripts into categories that represent a recurrent meaning. Walter (2010) and Harding (2013) provide guidelines for such decomposition and organization, which include the following steps: (1) define analysis parameters and codes of interest; (2) decide how to assign codes to each category; (3) define how to distinguish among categories; and (4) codification and interpretation of the results. In content analysis, coding refers to the process of systematically identifying keywords, phrases, and combinations thereof that indicate the presence of a relevant category in an interview transcript. Analysis parameters and categories refer to themes within the codes, for example, personality, perceptions of authority, racism, negligence, fear, and others. The codes were developed empirically while reading through the data as suggested by Harding (2013) and the categories were established based on observable patterns in the codes.

When coding, the team had two options. Text data could be interpreted explicitly or implicitly (Walter 2010). Explicit coding includes coding verbatim for a set of words, and coding generalizing of looking for similar words that represent the same. Implicit coding refers to coding not only for literal meaning but also interpreting the text to find non-literal meaning related to the coding categories.

\section{RESULTS}

Because this was a multi-phase study, the results of the focus group discussions, Photovoice prompts that resulted from the focus groups, and detailed results from the Photovoice interviews are presented in sequence. 


\subsection{Exploratory focus group discussions}

The exploratory focus group with the Hispanic workers revealed some interesting trends that both support and add to past knowledge. Interestingly, even though the prompts were very general in nature, the bulk of the discussions related to trends and perceptions that are different from those discussed in existing literature.

4.1.1 Culture and work priorities. Hispanic workers discussed that they prefer to perform their work quickly while paying less attention to safety when compared with non-Hispanic workers. Many of the foreign-born Hispanic workers say that in their native country they are taught to work hard, to get their hands dirty, and not to complain. This leads to an innate fear or discomfort of saying "no" when they are told to work under unsafe circumstances. Previous research has noted that workers tend to perform unsafe work quickly for fear of being fired (Roelofs et al. 2011) but no researchers have noted that a preference for productivity over safety being a cultural characteristic.

4.1.2 Relationship with supervisors. The participants felt that the people in positions of authority simply do not care about them or their issues. The focus group participants also explained that Hispanic workers often experience racism and discrimination from their supervisors in the form of unfair job assignments, poor work conditions, and indifference toward their needs. Goodrum and Dai (2005) and Menzel and Gutierrez (2010) discussed that Hispanic workers are disproportionately represented in high-risk trades; however, past researchers have not discussed that discrimination may play a role in systematic work assignments or unfair treatment.

4.1.3 Family issues. The focus group discussions shifted to family-related issues that affect safety decisions. On the positive side, the workers noted that they feel compelled to return home safely to their families. Unfortunately, there are also negative family-related issues. First, many Hispanic workers are in their high-risk trade because they need the money to feed their families and they are more likely to bring their personal and family problems to work, which causes distractions and feelings of anger that can negatively impact safety. Such emotional behavior relates to the concept of familismo discussed by Smith et al. (2006).

4.1.4 Communication challenges. Finally, the participants mentioned that it is difficult to understand and follow instructions or to ask questions because of a lack of fluency with the English language. Workers reported that English to Spanish translation is often poor or not provided, which leads to problems understanding the safety training materials and rules. Furthermore, workers perceive that non-Hispanics feel inconvenienced when communicating with Spanish-speaking workers. These discussions support past literature (Jaselskis et al. 2008; Center for Construction Research and Training 2013; Alsamadani et al. 2013). Since there is saturation in the communication-related knowledge related to Hispanic worker safety, the focus of the Photovoice was on the aforementioned focus group discussion themes and issues of cultural distance.

\subsection{Photovoice prompts}

The Photovoice prompts were created based on themes of challenges identified from literature and from the focus group discussions. The research team was careful to ensure that the prompts 
were not overly restrictive so that additional challenges could be introduced and discussed. The specific prompts provided to the Hispanic workers, along with the cameras are provided below.

Prompt 1: Please capture the impacts of personal relationships among Hispanic workers and between Hispanic and non-Hispanic on safety. Also, please capture when these played a role in safety-related decisions. Personal relationships may include family, friends, and coworkers and personal issues could be anything that happens outside work that could also impact safety performance.

Prompt 2: Please capture how relationships with people in positions of authority affect your safety and safety-related decisions. This may include any person at the worksite that could offer safety guidance, make safety decisions, or punish negative safety behavior.

Prompt 3: Please capture how past experiences affect your safety and identify differences between the US and your home country.

Prompt 4: Please capture how personal values and personality affect safety-related decisions. Examples may include machismo, pride, respect, shyness, and attitude towards risks discussed in the focus group discussions.

It is important to note that responses to these prompts would add significantly to the knowledge base for Hispanic worker safety and would not overlap with current knowledge captured in previous research. As one can see, communication issues are not included in the prompts.

\subsection{Photovoice interviews and coding protocol}

The prompts elicited a total of 188 pictures taken by 17 workers (an average of 11 pictures per worker). Workers were each asked to select the four most compelling photographs for in-depth interview with the researcher. In total, 68 photographs were used in the discussion. The reasons given by the workers for selecting the four photographs were that they most clearly depicted what the workers wanted to say and reasons for discarding the others were mainly because they showed repetitive information, or were poorly taken photographs.

The analysis of the interviews yielded 57 coding categories among which there were 9 first-level categories and 33 second-level categories shown in Table 4. The coding frequency was measured by the number of participants talking about a specific category. Personality was the most cited category, followed by personal relationship, safety awareness, and work conditions. The following is a detailed description of the findings related to the primary categories mentioned by $75 \%$ or more of the participants. In these sections key photographs are provided, along with interview discussions that most closely represent the major trends in all interviews.

When coding for the content analysis, we followed a three-step process suggested by Harding (2013) and Walter (2010). The first step involved the selection of analysis parameters. In terms of the number of categories, we used up to three levels of coding categories. The first level categories were to be no more than 10 in total and composed of a maximum of three words. This was done to ensure that the categories would be broad enough to cover the most important points in the interviews (e.g. be exhaustive of the data collected) and to ensure that each was exclusive 
of the others as suggested by Walter (2010). The second level categories were used to code every aspect of the interviews with respect to each first level category. The parameters for these categories were not to be more than 5 per each first level category, to be more descriptive than first level categories and to be mutually exclusive. Similarly, third level categories were used to identify and account for repetitive information within the second level categories. These followed the same parameters than second level categories. Finally, codes were developed empirically while reading through the data as suggested by (Harding 2013).

The second step of the analysis was to decide how to measure the codes. Here, the two alternatives were to code for existence or for frequency (Harding 2013; Walter 2010). Coding for existence means that a category is assigned to a piece only once and it does not account for the recurrence of that category within a singular piece. Conversely, coding for frequency means that every single repetition within a singular piece is marked and accounted for in each category. As a result coding for existence provides a measure of how many times a category was repeated among several pieces while coding for frequency provides a measure of how many times that category was repeated in the entire text evaluated. In this case, the text describing a picture was coded for frequency providing a measure of how many time a code was mentioned throughout the interviews.

The third step consisted on defining a way to distinguish among concepts in the coding process. In other words, this provides rules on how the data were interpreted and coded: explicitly or implicitly (Walter 2010). Explicit coding includes coding verbatim for a set of words, and coding generalizing of looking for similar words that represent the same. Implicit coding refers to coding not only for literal meaning but also interpreting the text to find non-literal meaning related to the coding categories. In order to minimize bias on the interpretation of data, the interviews on this investigation were code explicitly looking for similar terms that represent the same meaning. For more details on the coding procedure and for specific examples, please see Yugar-Arias (2015).

In this discussion, we present the major findings and experiences that were shared among four or more workers. Since the interviews were conducted individually and are based upon individual experience, we believe that there is some degree of saturation when $25 \%$ or more of the participants individually claimed the same experiences driven by their cultural differences. Although the $25 \%$ value is quite arbitrary, it provides a level of saturation to consider. For each finding, the number of participants explaining the same experience or perception is provided so that the reader may interpret the level of saturation achieved. 
Table 4: Coding categories

\begin{tabular}{|c|c|}
\hline First Level & Second Level \\
\hline $\begin{array}{l}\text { Personality } \\
\text { 94\% }\end{array}$ & $\begin{array}{l}\text { Acceptance of a more dangerous work } \\
\text { Attitude toward criticism } \\
\text { Machismo and Pride } \\
\text { Negligence and Need to work quickly } \\
\text { Trust }\end{array}$ \\
\hline $\begin{array}{l}\text { Work Conditions } \\
\mathbf{8 1 \%}\end{array}$ & $\begin{array}{l}\text { Work Environment } \\
\text { Unfair work distribution } \\
\text { Pressure } \\
\text { Exposure to climate Conditions }\end{array}$ \\
\hline $\begin{array}{l}\text { Personal Relationships } \\
\mathbf{8 1 \%}\end{array}$ & $\begin{array}{l}\text { Family } \\
\text { Personal Life } \\
\text { With English Speaking Co-workers } \\
\text { With Spanish Speaking co-workers }\end{array}$ \\
\hline $\begin{array}{c}\text { Safety Awareness } \\
81 \%\end{array}$ & $\begin{array}{l}\text { Acknowledgment of importance of safety } \\
\text { Acknowledgment of positive safety practices } \\
\text { Unsafe Behavior } \\
\text { Poor hazard recognition }\end{array}$ \\
\hline $\begin{array}{c}\text { Racial perceptions } \\
75 \%\end{array}$ & $\begin{array}{l}\text { Perception of other culture } \\
\text { Discrimination and Racism } \\
\text { Lack of trust between races } \\
\text { Acceptance -No racism }\end{array}$ \\
\hline $\begin{array}{c}\text { Relationship with authority } \\
75 \%\end{array}$ & $\begin{array}{l}\text { Reaching out } \\
\text { Perception of authority } \\
\text { Type of interaction }\end{array}$ \\
\hline $\begin{array}{c}\text { Past Experience } \\
\mathbf{3 4 \%}\end{array}$ & $\begin{array}{l}\text { Construction Related } \\
\text { No Past Experience } \\
\text { Work Conditions in Past Experiences }\end{array}$ \\
\hline $\begin{array}{c}\text { Improvement possibilities } \\
25 \%\end{array}$ & $\begin{array}{l}\text { Desire for improved communication } \\
\text { Desire for recognition } \\
\text { Desire for respect }\end{array}$ \\
\hline
\end{tabular}

\subsubsection{Personality}

Fifteen of seventeen participants mentioned personality-related issues during the interviews. Among them, ten participants described an internal pressure to complete work quickly, with daring attitudes that result in cutting corners, neglecting safety rules, and neglect of safe work practices. For example, one worker, captured the two pictures shown in Figure 2, showing a properly and a poorly installed scaffold side railing. The picture represents a safety risk to all workers using the scaffold because it is installed at a high elevation and a person could easily fall through. When asked why he photographed this situation he explained that: "we all know that this [pointing to Figure 2a] is the correct height. However, we don't care, and we do it only to mislead (the super). The super passes by and sees that it is there, but it is not correct." This not only shows negligence but also a complacent attitude where workers do certain safety-related 
tasks only because they are required. This finding suggests that safety education for Hispanic workers must focus on techniques that address strong personal biases against safety.

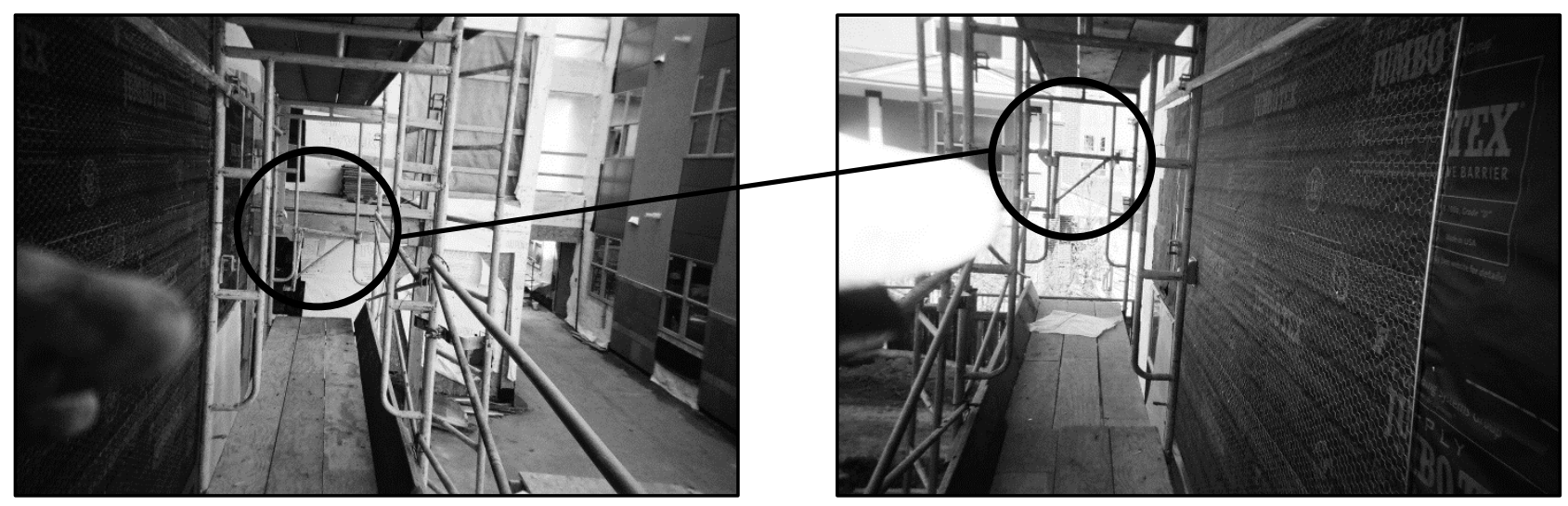

Figure 2: Photographs depicting incorrect use of safety equipment.

Worker shows a scaffold's side railing installed at an appropriate height where it can protect workers from falling off (left) and a side railing incorrectly, but more easily installed (right).

Another personality-related safety challenge among Hispanic construction workers relates to machismo and pride. Both result in careless decisions, not reporting injuries, and not asking safety-related questions when required. Six workers mentioned machismo and pride as a safety challenge. They explained that many Hispanic workers believe that they are so strong that they will not get injured or that they know everything there is to know about safety and will not acknowledge that someone with more experience or expertise may offer better safety solutions. Photographs depicted these issues through observations of Hispanic workers performing higher risk tasks that require heavy lifting and manual handling of materials that could have been performed safely with equipment.

One additional challenge, due in part to machismo, is a bad attitude towards criticism. Six workers mentioned that Hispanic workers have a fear of a bad reaction when providing criticism to Hispanic workers. The issue is even more complicated when the two workers are not familiar with one another. For instance, in one photograph a worker captured a situation where one worker (Worker A, Hispanic) was installing the scaffold's walking surfaces when another worker (Worker B, Hispanic) started performing work at the ground level in the same location. Worker A asked Worker B to move because the boards that Worker A was using above could fall down and hit him causing an injury. In response, Worker B scoffed and ignored Worker A's request and proceeded in an unsafe manner for 20 minutes. The participant explained that such interactions are common. It should be noted that we considered criticism to be an important attribute of safety communication because making safety observations and corrections of peers is critical to safety performance (Hinze et al. 2013). Being less comfortable providing criticism of co-workers is not a masculine characteristic and, therefore, may be an attribute of Hispanic culture or a manifest of power distance and restraint from Table 1.

These findings are consistent with the findings of strong masculine culture for Mexicans (Hofstede 1980; 2001), which includes a resistance to criticism. It should be noted that this may 
not be unique to Hispanic workers but also may be a characteristic of masculinity as our sample was masculine in nature. Fortunately, our sample is representative of the Hispanic construction workers in that most are from Mexico and nearly all foreign-born workers are male. As such, we believe that the results are accurate, although comparisons between male and female Hispanic workers and between Hispanic and non-Hispanic workers would be beneficial in future research.

\subsubsection{Work Conditions}

Thirteen participants mentioned unfair work distribution and unsafe working conditions as a major safety challenge specific to Hispanic workers. Seven workers acknowledged that Hispanic workers are usually assigned and eager to accept the most dangerous work on site. Although the workers were not asked about their immigration status, many explain that Hispanic workers who are illegally employed tend to accept any kind of job and will not complain because they are afraid of being deported. The participants also felt that there is pervasive favoritism towards nonHispanics who are typically assigned comfortable work that requires less manual handling of materials, less work at height, and less exposure to harsh weather conditions. One worker, for example, took the picture shown in Figure 3a, which depicts a Hispanic worker who was spotting an excavator that was loading an adjacent truck operated by a non-Hispanic worker on a very cold day. The participant explained that Hispanic workers are more often assigned this kind of dangerous job and exposed to poor weather conditions, while non-Hispanics stay indoors or work in the equipment with heat or air conditioning. In another worker's perspective, a fair distribution would be that everyone at the same skill level rotated work responsibilities and locations when some are favorable over others. When asked why Hispanic workers are chosen to do this kind of job, a third participant explained: "When we come and apply for a job, we say that we are laborers and that we are willing to do anything. When Non-Hispanics come and apply they write down operator even though they don't know how to operate the equipment. When they start the job, the bosses see that they don't know how to use the equipment and they give them chances so they can learn while we, who have been here longer, don't get those same chances." This perception as shared by multiple subjects.

It should be noted that this is a perception and that there was no triangulation of the results. As such, we cannot be sure that the cause of this perception is a product of cultural bias of the supervisors or, rather, education, training, skill, or other attributes of the sample. Thus, this comment and finding may be better categorized as past experience or relationship to authority, depending on the intentions and perceptions of supervisors. However, regardless of the categorization, it is interesting that the Hispanic workers did perceive this assignment as a cultural bias. To resolve this potential mis-classification, we strongly suggest future research to triangulate these findings to better distinguish the Hispanic workers' perceptions from the supervisors' intentions and perceptions. The lack of triangulation of workers, supervisors, and non-Hispanic co-workers is a limitation of this study. 

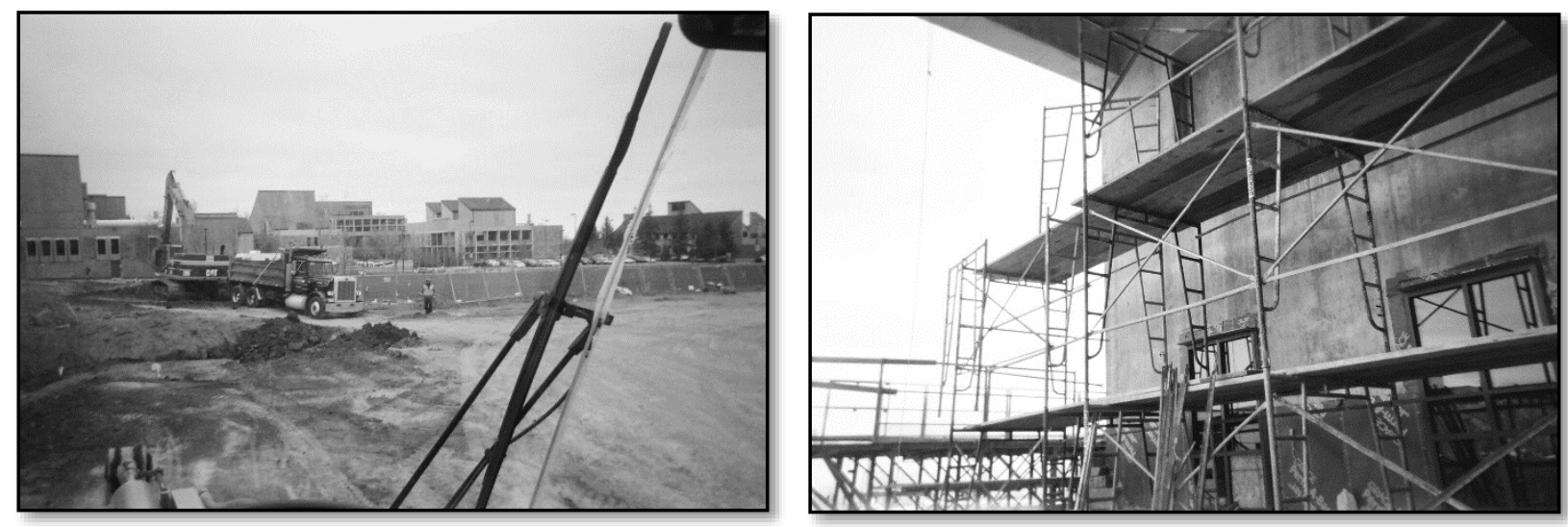

Figure 3: Examples depicting unfair work distribution

A Hispanic worker is spotting an exactor in a cold day (left). Participant worker explains that Hispanics are more prone to receive this kind of tasks than non-Hispanics. Participant explains that not many non-Hispanics work up in scaffold (right). He believes that one reason might be that this is an easy job and non-Hispanic managers assign it to Hispanic because they might think they are less intelligent.

One final safety challenge related to work conditions is the lack of proper tools and equipment provided to Hispanic crews, discussed by seven workers. Under strong productivity pressure, participants explained that many workers must improvise and use their own strength when proper equipment is unavailable. This is usually the case when workers have to move heavy materials from inventory to the point of installation. Although three of the participants felt that this issue is not unique to Hispanic workers, they did believe that, when faced with such situations, Hispanic workers are less likely to raise concern. Once participant explained that: "White people don't like to do much physical effort. While Hispanics, maybe due to our culture, it is like we are imposed to do more physical effort. In Mexico, for example, there is not as much technology as here, so we have to put more effort to compensate." This feeling was pervasive in the interview group and is depicted in the examples in Figure 4.
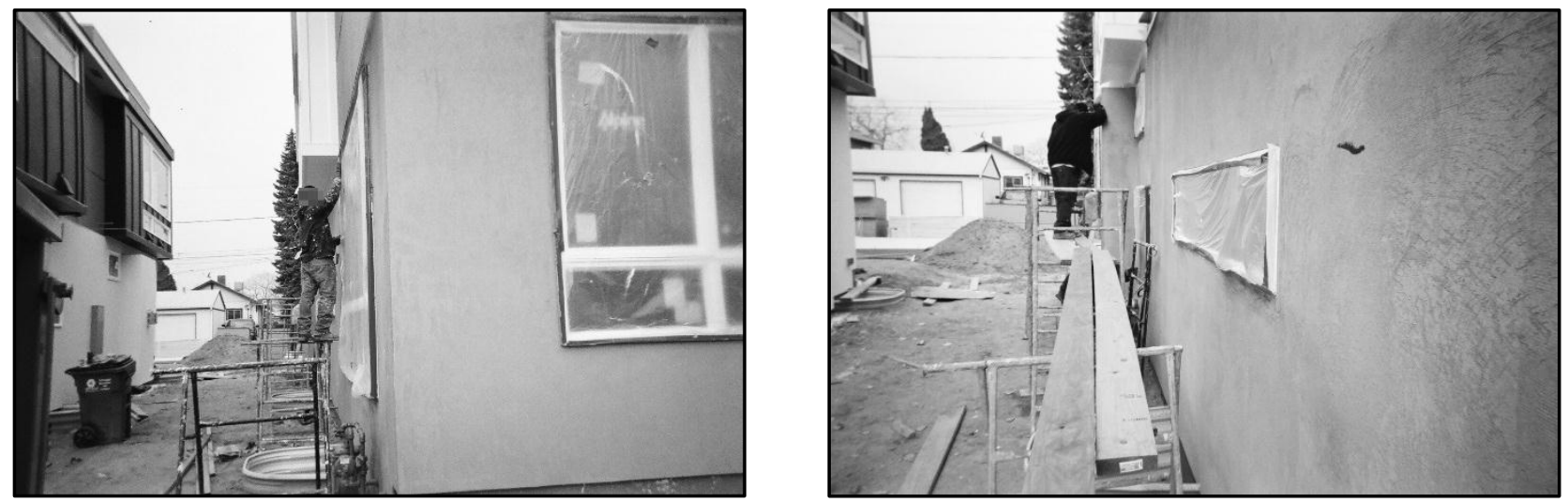

Figure 4 - Figures showing improvised work conditions

In both photographs Hispanic workers have captured images where proper tools and equipment were not provided by the employer and the workers instead had to improvise. 


\subsubsection{Personal relationships}

Thirteen participants described various challenges related to personal relationships with coworkers. Out of these, eight workers mentioned strong familial connections among Hispanic workers, especially among those who work on the same crew. Such connections can have both positive and negative implications according to the participants. Several participants captured photographs of close co-workers and explained that it is important for them to take care of their friends, to cover each other's' backs, and to work as a team. Although such connections improve morale, they can also inhibit criticism within the team. One worker, for example, explained: "we always try to cover each other when we are exposed to danger. Sometimes however, to get along with a friend, [we think] I'm not going to tell you anything because we are friends. You are going to feel bad." Another participant noted that close relationships with trust should make it easier to provide open criticism; unfortunately, any criticism is rare and taken poorly, especially among workers with family-like relationships. The participants largely feel that the fear of upsetting the friend is greater than the concern for their own safety.

Four participants noted another issue related to working relationships, explaining that safety communication between Hispanic and non-Hispanic workers can be severely limited because Hispanic workers are unsure of how non-Hispanic workers will react to criticism. For example, one participant photographed the cab of the forklift with an elevated basket with stacked material on top. The worker explained that, even though they were under the risk of being injured with a forklift failure, a group of adjacent Hispanic workers did not warn the non-Hispanic operator of the safety issue. This is symptomatic of a genuine fear of negative reaction to safety criticism or warning.

The final relationship issue dealt with the connection between the personal and family lives of Hispanic workers and safety. Nine participants described that Hispanic workers, unlike their nonHispanic counterparts, often have a dire need for employment because they need to both provide for their families in the US and send money back to their home country. Also, since many are foreign born or even illegally employed, they are not eligible for unemployment and other government programs if they were to lose their jobs. They explain that this financial stress increases willingness to perform unsafe work and decreases willingness to raise safety concerns.

\subsubsection{Safety Awareness}

Thirteen workers mentioned issues related to safety awareness and risk tolerance in their Photovoice interviews. Eight participants (acknowledged the importance of safety for their own well-being and that of their families. They agree that they need to change the way that they behaved in their home countries and adapt to what is expected in the US. Another five participants acknowledged that they feel that their employers are genuinely concerned for their safety and well-being. As such, they accept safety requirements and participate in safety activities such as morning stretches, safety training, and pre-job safety meetings and believe that they are important.

Nevertheless, eight participants recognized that Hispanic workers often defy safety rules and "do what they want." For example, one participant photographed a co-worker listening to music on his headphones. The previous day the crew was listening to music on their cell phone speakers until the superintendent banned music from the site because it was a distraction that prevented 
them from hearing safety warnings. Rather than following the rule, the following day the workers wore headphones instead, which resulted in even bigger distractions and isolation.

\subsubsection{Racial perceptions}

Racial perceptions were discussed by 12 workers and can be analyzed from two main perspectives. The first relates to how Hispanic workers perceive non-Hispanic workers and the second deals with how Hispanics feel that they are perceived by non-Hispanic workers. Both drive patterns in social interactions between these two racial groups, which have strong implications for safety behavior and communication on mixed-race sites.

With respect to Hispanic workers' perceptions of non-Hispanic co-workers, several participants explained that Hispanic workers sometimes hold non-Hispanic workers in a higher regard and believe that non-Hispanics deserve more respect. This makes communication, especially constructive safety-related criticism from Hispanic to non-Hispanic workers, difficult to achieve. Furthermore, participants felt that non-Hispanic workers are overly cautious and, although they recognize that this is proper work procedure, they were not raised or educated to act in that manner. The implication is that Hispanic workers assume that non-Hispanic workers are always working safely and are less likely to raise any safety concerns when non-Hispanic workers are present.

Participants also noted that they feel that they do not receive respect or regard from non-Hispanic workers or managers. First, one participant photographed a scaffold were a Hispanic crew was working in the exterior of the building. The participant explained that in his almost 12 years of experience, he had only seen a few non-Hispanic workers climb scaffolding. When asked why, the participant replied that that non-Hispanic workers feel that this work is relatively simple and menial. Another participant captured a photograph of a forklift that was stuck in mud and explained that the non-Hispanic superintendent went out of his way to direct a crew of Hispaniconly workers to stay away from the equipment but did not provide similar direction to the nonHispanic crews. The participant felt that such discriminant direction shows the mistrust from non-Hispanic management and evidence that management views Hispanic workers are unintelligent. Further, the participant explained that such discrimination eventually translates to their mistrust of non-Hispanic management that severely inhibits honest and open communication between the groups.

\subsubsection{Relationships with authority}

Despite the strong discussions of relationships to authority in the focus groups, only four of the participants photographed and discussed this issue in the Photovoice phase. The four participants, however, consistently noted that they feel that their supervisors are more concerned about the well-being of non-Hispanic workers. As a result, workers are not very willing to communicate with their superintendent and are sometimes jaded. It should be noted that not all participants noted this and some workers, instead, explain that they have strong and mutuallyrespectful relationships with their supervisors. These workers see the superintendent as someone who can give advice, and who treats them as brothers. Thus, issues related to supervision are inconclusive in this study. 


\subsubsection{Communication}

Given that a great deal of past research has focused on the impacts of communication in construction safety, the team placed relatively low emphasis on this category in the present investigation. Nevertheless, due to the flexibility purposely designed into the Photovoice prompts, many of the issues photographed and discussed were related to communication. There are two main issues that were commonly raised: language barrier and lack of communication. Although related, these two categories were discussed in two distinct ways. First, language is probably the biggest barrier Hispanics construction worker face in safety because it restricts communication among all parties involved in a construction project. For example, a participant captured a photograph of a Spanish-speaking worker guiding the stack of materials that the crane is moving. According to the participant, the guiding worker was holding a radio and was supposed to communicate with the crane operator at all times. Unfortunately, the crane operator speaks only English and the worker speaks only Spanish. At the moment the picture was taken, the load started moving sideways and another worker who spoke English intervened. Another worker explained that the required safety meetings at his site were in English and there were no translators. According to this participant, the workers who can speak both languages are required to translate but many important aspects are lost in translation. Specifically, the participant said: "I can assure you that about $80 \%$ of the people who is here does not speak English. When they [English speaking people] laugh we laugh, but about what? Who knows?" When asked if they ever asked for a better translation, the worker replied that no because they feel that the people in charge do not care.

\section{LIMITATIONS OF THIS STUDY}

There are several limitations of this study that must be acknowledged for proper interpretation and use of the results. Perhaps the most obvious and impactful is the relatively small sample size, which is exacerbated by the subjective nature of the data collection. Although more than sufficient for a Photovoice study (Hergerather et al. 2009), our sample size of 17 was recruited from the Denver Metropolitan region of Colorado only. Thus, the generalization of the experiences and perceptions are theoretically restricted to this geographical region. Nevertheless, given that the participants' country of origin was predominantly Mexico with several representatives from other Latin American countries, the sample is culturally representative of the Hispanic construction workforce in the US.

Another limitation of this study is that it does not provide results according specific to any one industry sector, company size, or overall company safety culture. Instead, the intention was to sample from several industry sectors. Additionally, this study does not include the views or opinions of non-Hispanic workers or managers. As a result, the findings miss the non-Hispanic perception which could provide an opportunity for more critical and neutral opinions. We encourage future research that includes non-Hispanic workers to establish when perceptions are correct or incorrect. Such knowledge could help to identify key areas of misunderstanding that could be reported and rectified by employers.

A final limitation is the lack of triangulation of the results, which may have led to misclassification of true biases. Our focus was on the perceptions of Hispanic workers, which undoubtedly drives the behavior of the Hispanic workforce. However, we were not able to 
triangulate the results to derive true causes of the perceptions in some cases. For example, Hispanic workers perceived unfair job assignments that could have been causes by cultural bias of supervisors toward Hispanic workers or from training, experience, or other factors independent of culture. The value of the perceptions of Hispanic workers alone were that they were derived directly from a Hispanic workforce and can be used as prompts for future exploration and triangulation of results with supervisors and non-Hispanic co-workers. This future research is highly suggested.

\section{MAJOR FINDINGS}

This study presents a plethora of newly-identified safety issues faced by Hispanic construction workers in the US that build significantly on previous literature. The authors attribute this new knowledge to the lack of researcher-introduced bias and the use of Photovoice, which proved to be an efficient method of collecting very rich experiential data and yielding new observations. The main knowledge contributions are discussed below in light of relevant past literature. Additionally, suggestions for action in practice and future research are suggested.

The first major finding is that Hispanic workers have an internal pressure to complete work quickly, with daring and complacent attitudes toward safety that result in cutting corners and neglecting rules. Hispanic workers also have a fear of challenging authority when asked to work in unsafe conditions. Participants felt that this is due to the fact that foreign-born Hispanic workers are taught to work hard and not to complain about work conditions in their native countries. Although Roelofs et al. (2011) observed that Hispanic workers tend to perform work quickly and do not challenge authority, no previous literature explored the cultural drivers of this observation.

The second major finding is that, Hispanic workers tend to be assigned and are likely to accept more dangerous tasks and are also less likely to provide feedback to their supervisors. The participants noted that Hispanic workers feel that they are assigned more dangerous work because their supervisors perceive them to be less intelligent and less valuable than their nonHispanic counterparts. Additionally, since they are often the primary earning member of a large family and are compelled to send money to their home country to support extended family, Hispanic workers tend to accept unfair work assignments without complaint. This finding provides an explanation for the disproportionate representation of Hispanic workers in high-risk trades observed by Goodrum and Dai (2005) and Menzel and Gutierrez (2010).

The third major finding is that Hispanic workers are tend to be distracted by family issues while at work. Such distractions are likely for Hispanic workers because they experience stronger family ties with a broader group of people than their non-Hispanic counterparts. This finding directly relates to Hofstede's (1980) description of high cultural distance in the collectivist dimension. The present study connects this known cultural phenomenon with safety implications on multi-cultural worksites.

The fourth finding relates to the fact that Hispanic workers self-identify that they are more likely to ignore criticism, exhibit more careless decisions, defy safety rules, and underreport injuries. Hispanic workers also report that they are less likely to acknowledge that they can learn from coworkers and supervisors who have more safety knowledge and are less likely to ask for safety 
assistance when it is needed. The participants attributed such behavior to the relatively high degree of machismo and pride in their culture. Interestingly, this finding suggests that machismo and pride are behavioral mediators between Hofstede's (1980) very high masculinity index for Hispanic cultures and Hispanic workers' safety behaviors.

The fifth and final major finding is that Hispanic workers fell less likely to criticize or provide feedback to both Hispanic and non-Hispanic workers. They tend not to challenge the nonHispanic co-workers because they are unsure of their reactions and they perceive that nonHispanic workers deserve more respect, even if they are otherwise equal. Hispanic workers also tend not to challenge other Hispanic workers because they fear that they will jeopardize their close familial ties. This finding has strong implications for authentic safety communication from Hispanic workers.

\section{DISCUSSIONAND RECOMMENDATIONS}

Collectively, the findings reveal important themes that may help to explain the disparity in injury rates between Hispanic and non-Hispanic workers. Specifically, combinations of factors such as the internal pressure to complete work efficiently and the general assignment to more dangerous tasks may manifest in a feeling of pressure to perform dangerous work more quickly, which involves much higher risk. Further, being less likely to criticize other workers of any nationality and the ignorance of others' criticism may make Hispanic workers less likely to learn and improve, may impede safety communication, and could yield misunderstandings, especially among cultures. Finally, distractions from family issues can be pervasive and can affect all types of work. Thus, this is a general and significant risk factor. In summary, the factors and their combinations logically explain some of the anecdotes, trends, and specific cases observed in the industry where Hispanic workers have been injured.

The findings from this paper also build upon the previous knowledge in the area of Hispanic construction worker safety and help to explain the fundamental reasons that Hispanic construction workers are, on average, $48 \%$ more likely to be injured or killed on construction sites (Center for Construction Research and Training 2013). This study also provides important connections between theory of cultural distance and worker safety and helps to explain the fundamental reasons for pervasive observations. Based on the new knowledge gained in this study, the authors recommend that employers of Hispanic workers facilitate a better understanding of the cultural differences between foreign-born and US-born workers; ensure equal distribution of work to Hispanic and non-Hispanic workers; use regular safety meetings to inform workers that the purpose and expectation of safety criticism and that voicing concern is encouraged; and ensure that Spanish-speaking workers receive full and accurate translation of all materials and communications. Such actions could improve Hispanic worker trust of management and co-workers, enhance safety communication, and decrease misconceptions among cultures. In addition to these practical recommendations, the authors strongly recommend future research into Hispanic worker safety that extends the geographic representation of this sample and includes the perspectives of non-Hispanic workers.

\section{ACKNOWLEDGEMENTS}


We would like to thank the National Science Foundation for supporting this research through an Early Career Award (CAREER) Program. This material is based upon work supported by the National Science Foundation under Grant No. 1253179. Any opinions, findings, and conclusions or recommendations expressed in this material are those of the authors and do not necessarily reflect the views of the National Science Foundation.

We would also like to thank the construction workers who provided candid accounts of their safety experiences.

\section{REFERENCES}

Alsamadani, R., Hallowell, M., and Javernick-Will, A. N. (2013). "Measuring and modelling safety communication in small work crews in the US using social network analysis." Construction Management and Economics, 31(6), 568-579.

Berg, B. L. (2009). Qualitative research methods for the social sciences. Allyn \& Bacon, Boston.

Bernard, H. R. (2000). Social research methods: qualitative and quantitative approaches. Sage Publications, Thousand Oaks.

Bureau of Labor Statistics. (2012). "Labor Force Statistics from the Current Population Survey." Washington, DC.

Brunette, M. J. (2004). "Construction safety research in the United States: targeting the Hispanic workforce." Injury Prevention, 10(4), 244-248.

Canales, A., Arbelaez, M., Vasquez, E., Aveiga, F., Strong, K., Walters, R., Jaselskis, E., and Jahren, C. (2009). "Exploring Training Needs and Development of Construction Language Courses for American Supervisors and Hispanic Craft Workers." Journal of Construction Engineering and Management, 135(5), 387-396.

Castleden, H., Garvin, T., and Huu-ay-aht First Nation. (2008). "Modifying Photovoice for community-based participatory Indigenous research.” Social Science \& Medicine (1982), 66(6), 1393-1405.

Center for Construction Research and Training. (2013). The Construction Chart Book: The U.S. Construction Industry and its Workers. Bethesda, MD.

Collier, J., Jr. (1957). "Photography in Anthropology: A Report on Two Experiments." American Anthropologist, 59(5), 843-859.

Fang, D., Chen, Y., and Wong, L. (2006). "Safety Climate in Construction Industry: A Case Study in Hong Kong." Journal of Construction Engineering and Management, 132(6), 573-584.

Farooqui, R., Ahmed, S., and Saleem, F. (2007). "Analysis of Workplace Injuries among Hispanic Construction Workers due to Safety Hazards." Fifth LACCEI International Latin American and Caribbean Conference for Engineering and Technology, Mexico City, Mexico.

Fernández-Muñiz, B., Montes-Peón, J. M., and Vázquez-Ordás, C. J. (2007). "Safety Culture: Analysis of the Causal Relationships Between its Key Dimensions." Journal of Safety Research, 38(6), 627-641.

Foddy, W. H. (1993). Constructing questions for interviews and questionnaires: theory and practice in social research. Cambridge University Press, Cambridge, UK; New York, NY, USA.

Freire, P. (1970). Pedagogy of the Oppressed. Herder and Herder, New York. 
Goodrum, and Dai, J. (2005). "Difference in Occupational Injuries, Illnesses, and Fatalities among Hispanic and Non-Hispanic Construction Workers." Journal of Construction Engineering and Management, 131(9), 1021-1028.

Halcomb, E. J., Gholizadeh, L., DiGiacomo, M., Phillips, J., and Davidson, P. M. (2007). "Literature review: considerations in undertaking focus group research with culturally and linguistically diverse groups." Journal of Clinical Nursing, 16(6), 1000-1011.

Hallowell, M., and Gambatese, J. (2010). "Qualitative Research: Application of the Delphi Method to CEM Research." Journal of Construction Engineering and Management, 136(1), 99107.

Harding, J. (2013). Qualitative data analysis from start to finish. SAGE, London; Thousand Oaks, CA

Harper, D. (2002). "Talking about pictures: A case for photo elicitation.” Visual Studies, 17(1), $13-26$.

Hergenrather, K. C., Rhodes, S. D., Cowan, C. A., Bardhoshi, G., and Pula, S. (2009). "Photovoice as community-based participatory research: a qualitative review." American journal of health behavior, 33(6), 686-698.

Hofstede, G. H. (1980). Culture's Consequences: International Differences in Work-related Values. Sage Publications, Beverly Hills, Calif.

Hofstede, G.H. (2001). Culture's Consequences: Comparing Values, Behaviors, Institutions and Organizations Across Nations, 2nd Edition. Sage Publications, Beverly Hills, Calif.

Hofstede, G. H. and Hofstede G.J. (20015). "Cultures and organizations: Software of the mind." $2^{\text {nd }}$ Ed. McGraw Hill, New York: New York.

Jaselskis, E. J., Strong, K. C., Aveiga, F., Canales, A. R., and Jahren, C. (2008). "Successful multinational workforce integration program to improve construction site performance." Safety Science, 46(4), 603-618.

Krueger, R. A., and Casey, M. A. (2000). Focus groups: a practical guide for applied research. Sage Publications, Thousand Oaks, Calif.

Lavy, S., Aggarwal, C., and Porwal, V. (2010). "Fatalities of Hispanic Workers: Safety Initiatives Taken by U.S. Construction Companies to Address Linguistic and Cultural Issues." International Journal of Construction Education and Research, 6(4), 271-284.

Lenartowicz, T., and Roth, K. (1999). "A Framework for Culture Assessment." Journal of International Business Studies, 30(4), 781-798.

McAfee, K. (2012). "Evaluating the Safety Culture of the Colorado Department of Transportation: Literature Review and Results of Pilot Survey."

Menzel, N. N., and Gutierrez, A. P. (2010). "Latino worker perceptions of construction risks." American journal of industrial medicine, 53(2), 179-187.

Palibroda, B., Krieg, B., Murdock, L., and Havelock, J. (2009). A Practical Guide to Photovoice: Sharing Pictures, Telling Stories and Changing Communities. Prairie Women's Health Network, Winnipeg, MB.

Roelofs, C., Sprague-Martinez, L., Brunette, M., and Azaroff, L. (2011). "A qualitative investigation of Hispanic construction worker perspectives on factors impacting worksite safety and risk." Environmental Health, 10(1), 84.

Samuels, J. (2004). "Breaking the Ethnographer's Frames Reflections on the Use of Photo Elicitation in Understanding Sri Lankan Monastic Culture." American Behavioral Scientist, 47(12), 1528-1550. 
Schwartz, L. R., Sable, M. R., Dannerbeck, A., and Campbell, J. D. (2007). "Using Photovoice to improve family planning services for immigrant Hispanics." Journal of health care for the poor and underserved, 18(4), 757-766.

Smith, S. M., Perry, T., and Moyer, D. (2006). "Safety Training Creating a Safer Workforce: Training Needs for Hispanic and Foreign-Born Workers.” Professional Safety, 51(12), 2025.

Soares, A. M., Farhangmehr, M., and Shoham, A. (2007). "Hofstede's dimensions of culture in international marketing studies." Journal of Business Research, Impact of Culture on Marketing Strategy, 60(3), 277-284.

Streng, J. M., Rhodes, S. D., Ayala, G. X., Eng, E., Arceo, R., and Phipps, S. (2004). "Realidad Latina: Latino adolescents, their school, and a university use photovoice to examine and address the influence of immigration." Journal of interprofessional care, 18(4), 403-415.

Umaña-Taylor, A. J., and Bámaca, M. Y. (2004). "Conducting Focus Groups with Latino Populations: Lessons from the Field*." Family Relations, 53(3), 261-272.

Walter, M. (Ed.). (2010). Social research methods. Oxford University Press, South Melbourne, Vic.

Wang, C., and Burris, M. A. (1997). "Photovoice: Concept, Methodology, and Use for Participatory Needs Assessment." Health education \& behavior: the official publication of the Society for Public Health Education, 24(3), 369-387.

Wang, C., Burris, Mary Ann, Ping, Xiang Yue. (1996). "Chinese village women as visual anthropologists: A participatory approach to reaching policymakers." Social Science \& Medicine Social Science \& Medicine, 42(10), 1391-1400. 